que, reiteramos, parece tener un destino principalmente docente.

Manuel Paniagua Zurera

\section{COMUNIDADES AUTÓNOMAS}

Freres, C. y Sanz, A. (Ed.) (2002), Las Comunidades autónomas españolas y América Latina: una nueva dimensión de la conexión iberoamericana, Madrid, Ed. Sociedad Editorial Síntesis, 410 págs.

Esta obra recogelos resultados deun proyecto de investigación coordinado por la Asociación de Investigación y Especialización sobre Temas Iberoamericanos (AIETI) y financiado por la Fundación Tinker de Nueva York. El proyecto se desarrolló desde enero de 2000 hasta mayo de 2002, dirigido por Christian Freres de AIETI.

El objetivo de este libro es el análisis del papel que las comunidades autónomas (CCAA) españolas desempeñan en las relaciones de España con América Latina, deteniéndose en el estudio de las conexiones económicas, políticas y culturales entre las CCAA y América Latina. Asimismo, intenta determinar la autonomía o subordinación de las actuaciones internacionales de las CCAA respecto a la política del Gobierno central. Finalmente, revisa el impacto de estas actuaciones en los países latinoamericanos.

Más en detalle, se han estudiado las actividades de cinco CCAA en Latinoamérica: País Vasco, Cataluña, Galicia, Andalucía y Madrid, para lo cual se ha contado con la participación de una institución de cada una de ellas, las cuales citaremos más adelante.

También se ha tratado de cubrir el objetivo de la investigación a través de la participación de cuatro entidades que han recogido el punto de vista de Argentina, Venezuela, Guatemala y Cuba sobre el tema estudiado.

La obra comprende once capítulos además de una introducción, cuyo contenido exponemos a continuación.

El capítulo que lleva por título «La acción exterior de las comunidades autónomas españolas en América Latina: una visión general» ha sido elaborado por Christian Freres y Antonio Sanz, miembros de AIETI. Se trata de una visión global del conjunto del texto, en la que se incorporan las siguientes conclusiones: a) la acción exterior de las CCAA es un ámbito poco desarrollado y que despierta la suspicacia del Gobierno central; b) la presencia de las CCAA en América Latina es muy reciente, si bien existen muchas posibilidades de ampliar estas relaciones internacionales; c) los países latinoamericanos ven con gran interés estas acciones de las CCAA, a pesar de su evidente novedad.

El capítulo 20 «La acción exterior en el Estado descentralizado. Las relaciones de Andalucía con Iberoamérica» ha sido redactado por $\mathrm{M}$ a del Mar Palacios Córdoba y Má Luz Ortega Carpio, profesoras de la Facultad de Ciencias Económicas y Empresariales-ETEA, centro adscrito a la Universidad de Córdoba. Indican que el área de principal interés para 
la CA andaluza corresponde a la Unión Europea; sin embargo, existe una presencia en América Latina que responde a una doble motivación: a)la promoción de los intereses de Andalucía en Latinoamérica; y b) la realización de una política de cooperación. Insisten en la necesidad de una mayor cooperación entre los distintos organismos públicos y privados que mantienen una acción exterior en América Latina y de un incremento del personal cualificado que se dedique a estas actividades.

El capítulo 3ㅇleva por título «Entre la promoción económica y la solidaridad: la acción exterior de Cataluña en América Latina». Sus autores son Anna Ayuso y Francesc Bayo, miembros del Centre d' Informació i Documentació Internacionales a Barcelona (CIBOC). Tras exponer los factores que pueden favorecer una inserción internacional de Cataluña de carácter más activo, se detiene en su acción exterior en América Latina, que comprende principalmente la promoción de las relaciones económicas, sobre todo las de carácter comercial, y en menor medida las inversiones en este espacio; siendo también importante la cooperación para el desarrollo. Estas relaciones son más relevantes con México, Argentina y Brasil, aunque se considera que se deben concentrar en ciertas áreas, especialmente en Centroamérica. También advierten de la necesidad de un diseño global.

El capítulo 4qo que ser efiere a «Galicia: acción exterior y Galeguidade en América Latina», ha sido escrito por María Xosé Viqueira y Xulio Ríos, del Instituto Gallego de Análisis y Documentación Internacional (IGADI) de Bayona (Galicia). Las relaciones exteriores constitu- yen un aspecto importante de la CA gallega que se caracteriza por la ausencia de conflicto con el Gobierno Central. Un lugar preferente de esta política lo ocupan las relaciones con América Latina, sobre todo con los países de Mercosur; estas acciones se refieren sobre todo a las relaciones económicas bilaterales y a las culturales, sin olvidar el relievequela emigración ha tenido siempre para Galicia. Se apunta el gran interés que tendría el reforzar el papel de Galicia como punto de encuentro entre América y Europa, en lo que también podría participar el Norte de Portugal.

El capítulo 50 «Comunidad autónoma, capital del Estado y «ciudad global»: la comunidad de Madrid y sus relaciones con Iberoamérica»tiene como autor a José Antonio Sanahuja, profesor de la Universidad Complutense e investigador del Instituto Complutense de Estudios Internacionales (ICEI) de Madrid. Esta CA ha experimentado un proceso creciente de internacionalización, que se manifiesta en la importancia de las inversiones exteriores y de sus inversiones en el exterior. Centrándose en Latinoamérica, se subrayan las inversiones de las empresas transnacionales españolas y sobre todo las actividades de cooperación. También el Ayuntamiento de Madrid tiene un papel relevante en esta materia, aunque el autor valora como insuficiente la coordinación entre instituciones.

«La acción exterior vasca y América Latina: motivaciones, instrumentos y evolución» es el título del capítulo 6으, cuyos autores son Karlos Pérez de Armiño e Irantzu Mendia, investigadores del Instituto de Estudios sobre Desarrollo y Cooperación Internacional (HE- 
GOA) de Bilbao.En 1990 se creó la Secretaría General de Acción Exterior que coordinó las actividades exteriores de la CA vasca, en primer lugar en Europa y en segundo lugar en América Latina. Estas tienen el siguiente contenido: a) la proyección hacia el exterior del autogobierno vasco; b) la actividad económica.-comercial; c) las relaciones con las colectividades vascas en el exterior; y d) la cooperación al desarrollo. La valoración de esta política es doble: la ausencia de un diseño global y el recelo del Gobierno Central hacia estas iniciativas del Gobierno Vasco.

El capítulo 7o, de carácter recapitulatorio, trata el tema de «Las Comunidades Autónomas y la política exterior de España», siendo sus autores Christian Freres y Antonio Sanz de AIETI. Indican que las CCAA tienen un interés evidente en participar en la acción exterior, especialmente a lo que se refiere a la UE, participando en lo que se ha llamado la «Europa de las regiones». En este sentido, el Gobierno Central limita las decisiones de las CCAA, apoyándose en una interpretación de la Constitución Española algo restrictiva. América Latina es el otro espacio en el que actuan las CCAA, a las que habría que reprochar un escaso aprovechamiento del principal instrumento de cooperación iberoamericana: la Comunidad Iberoamericana de Naciones. Abogan por una mayor consideración de las CCAA en la elaboración de la política latinoamericana del Gobierno Central.

La segunda parte del libro Perspectiva desde América Latina, comienza con el 8o capítulo «Recreando vínculos: las relaciones entre Argentina y las comunidades autónomas en la actualidad», escrito por Enrique Peruzzotti, de la Universidad Torcuato di Tella, de Buenos Aires (Argentina). Dedica un espacio extenso a la evolución política argentina y a las relaciones bilaterales con España, que han tenido en las inversiones de las empresas españolas un aspecto básico. Comenta el conflicto de Aerolíneas y la situación de la banca española en el mercado argentino, que no tienen un carácter económico en exclusiva ya que presentan innegables aristas políticas. Sobre las CCAA destacalas acciones de la CA vasca, Cataluña y Galicia, opinando que en general la política de las CCAA puede jugar un papel importante por los vínculos existentes con el país argentino.

Oneida Alvarez Figueroa y Alejandro Durán Cárdenas, de la Cátedra de Cooperación Hispanocubana, son los autores del capítulo 90 «Las relaciones de las comunidades autónomas españolas y Cuba: contribución a una nueva dimensión de la conexión Iberoamericana». A partir de las relaciones internacionales de Cuba, observan que si bien las relaciones con España se han estancado, las de las CCAA se han fortalecido en los últimos años; el contenido de estas últimas abarca el comercio, las inversiones directas y la ayuda al desarrollo. Subrayan la colaboración de la CA andaluza en el desarrollo agrario y la de Cataluña en el sector industrial. Estas relaciones de Cuba con las CCAA tienen importantes potencialidades, que los autores señalan especialmente en los niveles de diputación-provincia y municipio-municipio.

El capítulo 10 - titulado «Guatemala y las comunidades autónomas: problemática social y cooperación», ha sido ela- 
borado por Leonel Eduardo Padilla, del Instituto de Relaciones Internacionales e Investigaciones para la Paz (IRIPAZ) de Guatemala. Valora positivamente el trabajo de algunas CCAA en Guatemala, en cuanto a las políticas hacia los pueblos indígenas, la reforma del estado y la cooperación académica y científica; sin embargo, éstas no siempre son aprovechadas por el Gobierno guatemalteco para recibir transferencias de ciencia y tecnología. Insiste en los objetivos de esta política de cooperación: el fortalecimiento del municipio, la reducción de los prejuicios acerca dela variedad etnolingüística de Guatemala y el reconocimiento de los pueblos indígenas.

El último capítulo analiza «La acción exterior de las comunidades autónomas: una visión desde Venezuela»; CarIos A. Romero, Said Dohadah, Gabrielle Guerón y Mónica Lorenzo, del Instituto de Estudios Políticos de Caracas (Venezuela) son sus autores. Estos observan que las actividades de las CCAA en Venezuela son poco visibles, lo cual en parte está determinado por la política de los gobiernos centrales españoles que rechazan la acción exterior de las CCAA. Ello no impide que estas realicen actividades de intermediación con el Gobierno español y con las instituciones europeas. Además algunas CCAA han creado instituciones en Venezuela, por ejemplo el Gobierno Vasco, el de Canarias y la CA gallega. Estiman que las CCAA han tenido alguna influencia en la gobernabilidad deVenezuela. Por ello, a pesar de sus limitaciones, la acción exterior de las CCAA ha tenido un apreciable papel en la economía y sociedad venezolana.

La obra se completa con varios anexos, uno de ellos, el resumen del seminario «Las comunidades autónomas españolas y América Latina: una nueva dimensión de la conexión iberoamericana», celebrado en Madrid los días 26 y 27 de septiembre de 2001.

En resumen, un estudio minucioso delas actividades exteriores de las CCAA en América Latina. Relaciones que vienen marcadas por la reticencia del Gobierno Central y por la falta de coordinación de las instituciones que intervienen en esta política a nivel comunitario. Todo ello no impide que esta incipiente política tenga un papel importante en las relaciones con Latinoamérica, tal como indican en sus respectivos trabajos los parcipantes de los países americanos. Esperemos que los problemas recientes de Argentina y otros países del Cono Sur no entorpezcan estas actividades de las CCAA.

Desde el punto de vista formal, el libro está bien editado y ha sido bien coordinado por sus editores, que han evitado en gran parte la falta de homogeneidad típica de las obras en colaboración. Existen algunas repeticiones, defecto menor, que no empañan la buena calidad de la edición.

Una obra interesante que analiza en detalle un aspecto poco conocido delas CCAA españolas.

Adolfo Rodero Franganillo 